\title{
PREVALENCE OF CONSTITUTIVE AND INDUCIBLE CLINDAMYCIN RESISTANCE AMONG CLINICAL ISOLATES OF STAPH AUREUS IN KASHMIR VALLEY: A HOSPITAL BASED STUDY
}

\author{
Shaika Farooq ${ }^{1}$, Mehvish Saleem ${ }^{2}$
}

${ }^{1}$ Assistant Professor, Department of Microbiology, Government Medical College, Srinagar.

2Tutor/Demonstrator, Department of Microbiology, Government Medical College, Srinagar.

\section{ABSTRACT}

Methicillin resistant Staphylococcus aureus has become endemic in India with the prevalence ranging from $25 \%$ in the west India to $50 \%$ in south India. Clindamycin therapy is a useful alternative to treatment of such infections. However, bacterial resistance to this drug has been known to occur through various mechanisms with variable prevalence in different geographical regions and among Methicillin Sensitive (MSSA) and Methicillin Resistant Staphylococcus aureus (MRSA). The most common being MLSB (Macrolide, Lincosamide and Streptogramin B) resistance mediated by erm genes. While constitutive MLSB resistance is easily picked up by routine antimicrobial disc diffusion susceptibility tests, the inducible MLSB resistance is only picked up by D zone test.

\section{MATERIAL AND METHODS}

We evaluated 343 clinical isolates of Staphylococcus aureus for MLSB resistance phenotypes using D zone test. Identification of Staphylococcus aureus isolates was done by standard biochemical techniques and then subjected to routine susceptibility testing by Kirby Bauer's disc diffusion method on Mueller Hinton agar plates.

\section{RESULTS}

All isolates were resistant to penicillin. 61.23\% (210) were MRSA and 38.77\% (133) were MSSA. Among the MRSA isolates 49.5\% and 7.14\% isolates showed cMLSB and iMLSB resistance respectively, whereas among 133 MSSA isolates $8.27 \%$ and $2.26 \%$ isolates showed cMLSB and iMLSB resistance respectively.

\section{DISCUSSION}

The present study revealed a high prevalence of cMLSB in our region. Also prevalence of cMLSB and iMLSB resistance in MRSA is higher than that in the MSSA isolates showing that the distribution of MLSB resistance phenotypes varies among MSSA/MRSA isolates and among different geographical regions. Overall, we found $43.33 \%$ clindamycin resistance among MRSA and $10.5 \%$ resistance among MSSA isolates. We suggest clindamycin should be used as a therapeutic drug with caution for Staphylococcal infections and recommend that the D zone test should be used as a routine screening procedure to evaluate inducible clindamycin resistance in Staphylococcus aureus to overcome any subsequent treatment failure.

\section{KEYWORDS}

Clindamycin Resistance, Constitutive Clindamycin Resistance, Inducible Clindamycin Resistance.

HOW TO CITE THIS ARTICLE: Farooq S, Saleem M. Prevalence of constitutive and inducible clindamycin resistance among clinical isolates of staph aureus in Kashmir valley: a hospital based study. J. Evolution Med. Dent. Sci. 2016; 5(17):828-831, DOI: $10.14260 /$ jemds/2016/191

\section{INTRODUCTION}

Staphylococcus aureus is one of the leading causes of community acquired and nosocomial infections worldwide. The organism is known to cause protean infections ranging from minor skin infections like furunculosis, boils, carbuncles, localised soft tissue abscesses, ear, eye and bone infections to severe ailments like pneumonia, endocarditis, meningitis and septicaemia. The problem has been compounded by the emergence of $\beta$ lactamase producing and then methicillin resistant Staphylococcus strains. Such infections are known to be resolved by clindamycin, streptogramins, vancomycin, linezolid and recently ceftaroline.

Financial or Other, Competing Interest: None.

Submission 31-12-2015, Peer Review 20-01-2016,

Acceptance 30-01-2016, Published 26-02-2016.

Corresponding Author:

Dr. Shaika Farooq,

Assistant Professor, Department of Microbiology,

Government Medical College, Srinagar.

E-mail: drshaika1farooq@yahoo.com

DOI: 10.14260/jemds/2016/191
Clinically, clindamycin (CL) has been found to be an effective drug owing to its low cost, fewer severe side effects, availability of oral and parenteral forms, lack of need for renal adjustments, good tissue penetration and ability to directly inhibit toxin production. ${ }^{1,2}$ It is a useful choice in cases of penicillin allergy. ${ }^{1}$ However, since its introduction in the year 1968, bacterial resistance to this drug has been known to occur through various mechanisms. These include ribosomal target site modification, efflux pump and drug inactivation. So far, target site modification due to ribosomal methylation remains the most widespread mechanism of resistance to macrolides and lincosamides. ${ }^{2}$ This expression of MLSB (Macrolide, Lincosamide and Streptogramin B) resistance can be constitutive or inducible.

While constitutive resistance can be easily detected on routine antimicrobial sensitivity testing on disc diffusion, the true picture of inducible MLSB phenotype is masked, i.e. it appears resistant to macrolide but sensitive to clindamycin. This poses a risk to the patient owing to the therapeutic failure subsequent to selection of resistant mutants. Such Staphylococcus aureus iMLSB phenotypes can best be screened on $\mathrm{D}$ zone disc diffusion test as recommended by CLSI. Prevalence studies of iMLSB and cMLSB Staphylococcal 
phenotypes conducted in many parts of the world have been found to vary from region to region.

We felt a need to carry such a study in our region, where we encounter a high burden of Staphylococcus aureus infections and macrolides and clindamycin being empirically used for such infections. This prospective study was aimed at the assessment of the prevalence of constitutive and inducible clindamycin resistance among various types of clinical isolates of Staphylococcus aureus (both MRSA and MSSA) using the D zone test.

\section{MATERIAL AND METHODS}

The present study was conducted in a tertiary care teaching institution in Srinagar from Nov 2014 to Nov 2015 over a period of one year; 343 non-duplicate clinical samples of Staphylococcus aureus obtained from various sites like skin, bone, ear, soft tissue, respiratory tract and CNS infections were included. Identification of S. aureus isolates was done by standard biochemical techniques. ${ }^{3}$ and then subjected to routine susceptibility testing by Kirby Bauer's disc diffusion method on Mueller Hinton agar plates using HiMediapenicillin $(10 \mathrm{U})$, cefoxitin $(30 \mu \mathrm{g})$ erythromycin $(15 \mu \mathrm{g})$, cotrimoxazole $(1.25 \mu \mathrm{g} / 23.75 \mu \mathrm{g})$, clindamycin $(2 \mu \mathrm{g})$, gentamicin $(10 \mu \mathrm{g})$, ciprofloxacin $(5 \mu \mathrm{g})$ and amikacin $(10 \mu \mathrm{g})$ discs as per CLSI guidelines. ${ }^{4}$ Cefoxitin disc was used as a surrogate marker for oxacillin resistance.

Penicillin sensitive Staphylococcus (Zone diameter $>29 \mathrm{~mm}$ ) was further screened for $\beta$ lactamase production by penicillin zone edge test. Any sharp zone edge (Cliff) was taken as $\beta$ lactamase positive and fuzzy zone edge (Beach) was taken as $\beta$ lactamase negative. ${ }^{4}$ On the basis of cefoxitin disc diffusion, isolates were further categorised into methicillin sensitive (zone diameter $>$ or $=22 \mathrm{~mm}$; mecA negative)and methicillin resistant (zone diameter $<21 \mathrm{~mm}$; mecA positive) Staphylococcus aureus.

Those isolates (MRSA and MSSA) that appeared erythromycin resistant and clindamycin sensitive were further subjected to 'D zone test' as per CLSI guidelines. Briefly, erythromycin $(15 \mu \mathrm{g})$ disc was placed at a distance of $15 \mathrm{~mm}$ apart (edge to edge) from clindamycin $(2 \mu \mathrm{g})$ disc on a Mueller Hinton agar plate previously inoculated with 0.5 McFarland bacterial suspensions. Following overnight incubation at $37^{\circ} \mathrm{C}$ ambient air, flattening of zone (D shaped) around clindamycin in the area between the two discs or hazy growth within the zone of inhibition around clindamycin indicated inducible clindamycin resistance. ${ }^{4}$

Three different phenotypes were appreciated after testing and interpreted as follows:

1. MS Phenotype - Staphylococcal isolates exhibiting resistance to erythromycin (zone size $\leq 13 \mathrm{~mm}$ ), while sensitive to clindamycin (zone size $\geq 21 \mathrm{~mm}$ ) and giving circular zone of inhibition around clindamycin was labelled as having this phenotype.

2. Inducible MLSB Phenotype - Staphylococcal isolates showing resistance to erythromycin (Zone size $<13 \mathrm{~mm}$ ) while being sensitive to clindamycin (Zone size $>21 \mathrm{~mm}$ ) and giving $\mathrm{D}$ shaped zone of inhibition around clindamycin with flattening towards erythromycin disc were labelled as having this phenotype (Figure 1).
3. Constitutive MLSB Phenotype - this phenotype was labelled for those Staphylococcal isolates, which showed resistance to both erythromycin (zone size $<13 \mathrm{~mm}$ ) and clindamycin with circular shape of zone of inhibition (zone size $<14 \mathrm{~mm}$ ) if any around clindamycin (Figure 2).

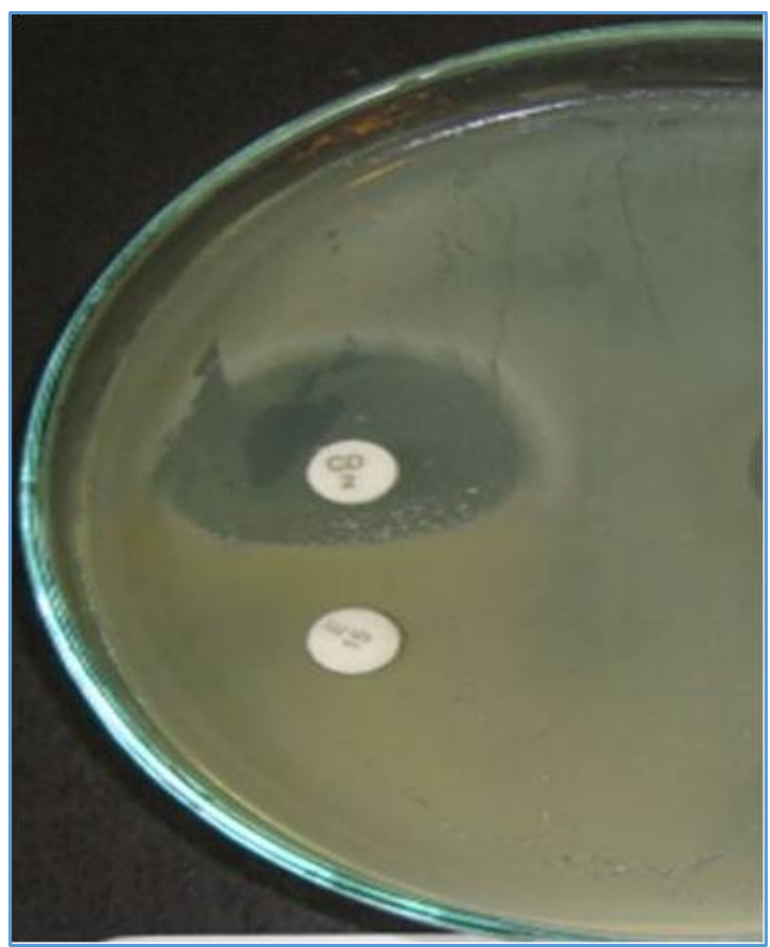

Fig. 1: iMLSB Phenotype

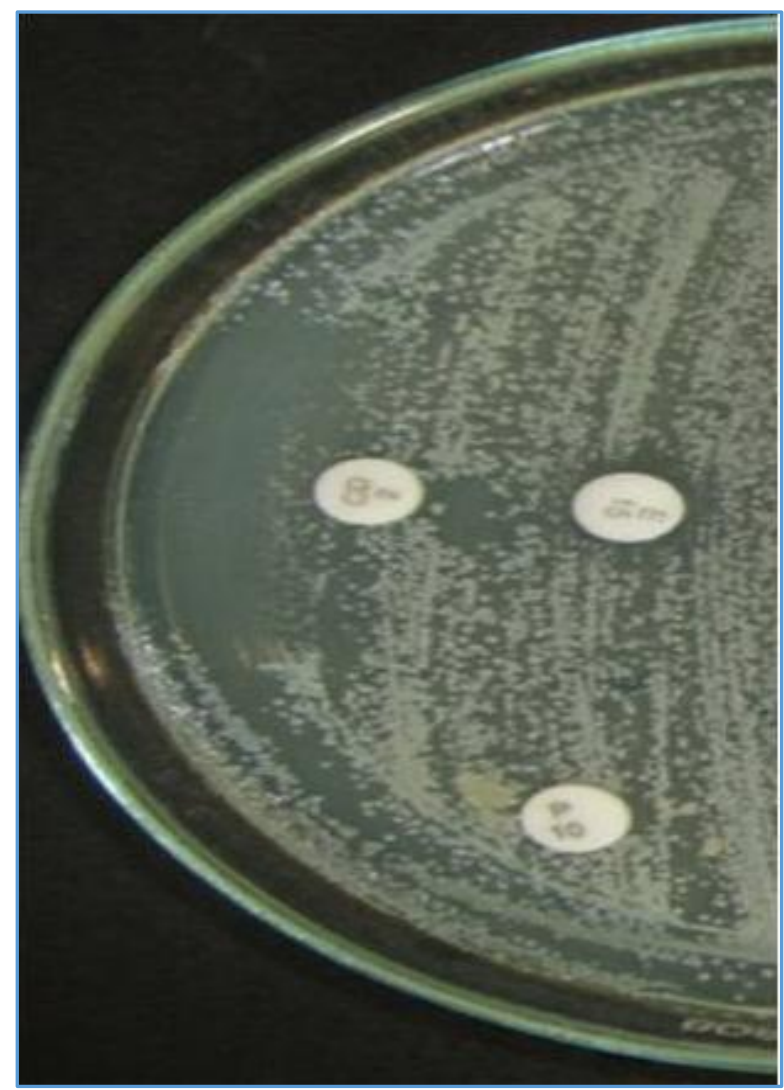

Fig. 2: cMLSB Phenotype 


\section{RESULTS}

All of the 343 strains of Staphylococcus aureus examined were found to be penicillin resistant; 210 (61.23\%) were MRSA (Methicillin Resistant) and 133 (38.77\%) were MSSA (Methicillin Sensitive). The MRSA Strains belonged to 52\% females and $48 \%$ males and the MSSA Strains were from $55 \%$ males and $45 \%$ females (Table 1 ).

\begin{tabular}{|c|c|c|c|}
\hline Source & $\begin{array}{c}\text { Strains of } \\
\text { Staphylococcus } \\
\text { aureus }\end{array}$ & MRSA & MSSA \\
\hline Skin & $112(32.65 \%)$ & $83(74 \%)$ & $29(26 \%)$ \\
\hline Bone & $55(16.03 \%)$ & 38 (69\%) & $17(31 \%)$ \\
\hline Ear & $52(15.16 \%)$ & $19(37 \%)$ & $33(63 \%)$ \\
\hline Soft tissue & $94(27.40 \%)$ & $52(55 \%)$ & $42(45 \%)$ \\
\hline Respiratory & $25(7.28 \%)$ & $15(60 \%)$ & $10(40 \%)$ \\
\hline $\mathrm{CSF}$ & $5(1.45 \%)$ & $3(60 \%)$ & $2(40 \%)$ \\
\hline Total & 343 & 210 & 133 \\
\hline \multicolumn{4}{|c|}{$\begin{array}{c}\text { Table 1: Distribution of Staphylococcus aureus } \\
\text { Strains as Per the Tissue Origin }\end{array}$} \\
\hline
\end{tabular}

Out of total 343 strains of Staphylococcus aureus, $33.53 \%$ showed overall constitutive MLSB phenotype (CL:R; ERY:R). Among 210 strains of MRSA 49.5\% were cMLSB phenotype, while $8.27 \%$ of 133 MSSA isolates were of cMLSB phenotype. Constitutive MLSB resistance was found to be higher in MRSA than MSSA (Table 2).

\begin{tabular}{|c|c|c|c|}
\hline $\begin{array}{c}\text { Sensitivity/ } \\
\text { Resistance } \\
\text { Pattern }\end{array}$ & $\begin{array}{c}\text { No. of } \\
\text { Isolates }\end{array}$ & MRSA & MSSA \\
\hline CL:R; ERY:R & $115(33.53 \%)$ & $104(49.52 \%)$ & $11(8.27 \%)$ \\
\hline CL:S; ERY: R & $111(32.36 \%)$ & $67(31.90 \%)$ & $44(33.08 \%)$ \\
\hline CL:S; ERY:S & $114(33.24 \%)$ & $36(17.14 \%)$ & $78(58.65 \%)$ \\
\hline CL:R; ERY:S & $3(0.87 \%)$ & $3(1.43 \%)$ & 0 \\
\hline Total & 343 & $\mathbf{2 1 0}$ & 133 \\
\hline \multicolumn{4}{|c|}{ Table 2: Susceptibility to ERY and CL } \\
among Staphylococcus aureus Isolates \\
\hline
\end{tabular}

Overall 33.24\% isolates of Staphylococcus aureus were sensitive to both the drugs (ERY: S; CL:S); $17.14 \%$ of MRSA and a higher percentage, i.e. $58.65 \%$ of MSSA isolates were sensitive to both erythromycin and clindamycin.

\begin{tabular}{|c|c|c|c|}
\hline & MRSA & MSSA & Total \\
\hline $\begin{array}{c}\text { iMLSB phenotype } \\
\text { CL:S; ERY:R D test + }\end{array}$ & $15(7.14 \%)$ & $3(2.26 \%)$ & $18(5.20 \%)$ \\
\hline $\begin{array}{c}\text { MSB phenotype } \\
\text { CL:S; ERY:R D test - }\end{array}$ & $52(24.76 \%)$ & $41(30.83 \%)$ & $93(27.11 \%)$ \\
\hline cMLSB phenotype & $104(49.52 \%)$ & $11(8.27 \%)$ & $115(33.53 \%)$ \\
\hline \multicolumn{4}{|c|}{ Table 3: Distribution of Resistant } \\
Phenotypes on Performing D Zone Test
\end{tabular}

$7.14 \%$ of 210 MRSA isolates showed iMLSB resistance, whereas $3(2.26 \%)$ of 133 MSSA isolates showed iMLSB resistance (Table 3). Of the 133 MSSA isolates, we found $89.47 \%$ were sensitive to clindamycin whereas of 210 MRSA isolates $43.33 \%$ of MRSA strains were still sensitive to clindamycin. In other words $10.5 \%$ of MSSA were found to be resistant to clindamycin, whereas $58.1 \%$ of MRSA isolates were resistant to clindamycin (incl cMLSB, iMLSB phenotypes and only CL resistant isolates, 3). Among the total MSSA strains 41.35\% (including cMLSB, iMLSB and MSB phenotypes) were found to be resistant to erythromycin and of the total MRSA strains a whopping $81.42 \%$ were found to be resistant to erythromycin.

\section{DISCUSSION}

Emergence of methicillin resistant Staphylococcal infections has become a growing concern the world over. In India methicillin resistant Staphylococcus aureus has become endemic with the prevalence ranging from $25 \%$ in western India. 5 to $50 \%$ in south India. ${ }^{6}$ In our study we found that out of 343 Staphylococcal isolates, none was sensitive to penicillin, 61.23\% (210) were MRSA and 38.77\% (133) were MSSA. Similar findings were reported by Naima et al. ${ }^{1}$ (MRSA: 64\%; MSSA: 36\%), Venkataraghavandra et al.7; (MRSA 75.27\% MSSA 24.73\%), Mukesh et al.8; (MRSA 70\%; MSSA 30\%) Deotale et al. ${ }^{9}$ (MRSA 50.8\% and MSSA 50.2\%) and Yilmaz et al.10 (MRSA 52.55\%, MSSA 47.45\%). On evaluation of MLSB resistant phenotypes, we found a high percentage (49.52\%) of cMLSB resistance among MRSA isolates. This is in concordance with findings by Azap et al. ${ }^{11}$ (64\%), Yilmaz et al. (44.2\%), Shantala et al. ${ }^{12}$ (25.39\%) and Gupta et al.13 (46\%). However, Deotale et al. and Venkataraghavandra et al. showed a lower prevalence of cMLSB resistance $7.3 \%$ and $2.85 \%$ respectively) in MRSA isolates. This indicates that the prevalence of resistance phenotypes vary among MSSA/MRSA isolates and among different geographical regions as depicted from various studies shown in Table 4.

\begin{tabular}{|c|c|c|c|c|c|c|}
\hline \multirow[b]{2}{*}{ Phenotype } & \multicolumn{4}{|c|}{ MRSA } & \multicolumn{2}{|c|}{ MSSA } \\
\hline & cMLSB & iMLSB & MSB & cMLSB & iMLSB & MSB \\
\hline Present study & $49.52 \%$ & $7.14 \%$ & $24.76 \%$ & $8.27 \%$ & $2.26 \%$ & $30.83 \%$ \\
\hline Deotale et al. ${ }^{9}$ & $7.3 \%$ & $24.65 \%$ & $27 \%$ & - & $1.6 \%$ & $4 \%$ \\
\hline Yilmaz et al.10 & $44.2 \%$ & $24.4 \%$ & $5.2 \% \%$ & $4.5 \%$ & $14.8 \%$ & $3.6 \%$ \\
\hline Gupta et al.13 & $46 \%$ & $20 \%$ & $16 \%$ & $10 \%$ & $17.33 \%$ & $37.3 \%$ \\
\hline Gadepelli et al. ${ }^{14}$ & & $30 \%$ & & & $10 \%$ & \\
\hline Prabu et al. 15 & $16 \%$ & $20 \%$ & & $6 \%$ & $6.15 \%$ & \\
\hline Azap et al. ${ }^{11}$ & $64 \%$ & $5.7 \%$ & $0 \%$ & $4.6 \%$ & $3.6 \%$ & $3.6 \%$ \\
\hline Shantala et al. ${ }^{12}$ & $25.39 \%$ & $32.5 \%$ & & $9.6 \%$ & $15.53 \%$ & \\
\hline Venkataragwandra A et al. ${ }^{6}$ & $2.85 \%$ & $45.71 \%$ & & - & & \\
\hline
\end{tabular}


Inducible clindamycin resistance was found to be higher in MRSA (7.14\%) than MSSA isolates (2.26\%) and was in concordance with other studies as shown in Table 4. We observed a high MSB resistance attributed mainly to efflux mechanisms or msr genes among Staphylococcus aureus (MRSA: $24.36 \%$; MSSA: $30.83 \%$ ) isolates as was found by Gupta et al. from Chandigarh. This could be attributed to the empirical and incessant use of macrolides, both over the counter and for minor viral infections leading to selection of resistant mutants. Overall, $81.42 \%$ of MRSA and $41.35 \%$ of MSSA isolates were found to be resistant to erythromycin.

Considering this, macrolides should be used with caution as an empirical therapy. Moreover prevalence of MLSB and MSB resistant phenotypes in CA MRSA and HAMRSA strains in our community should be evaluated especially in the background of high constitutive MLSB and MSB resistance when selection of resistant mutants can be fast. In the background of overall $43.33 \%$ clindamycin resistance among MRSA and 10.5\% resistance among MSSA isolates, clindamycin should be used as a therapeutic drug with caution for Staphylococcal infections. We recommend that $\mathrm{D}$ zone test should be done as a routine screening procedure to overcome any subsequent treatment failure.

\section{REFERENCES}

1. Fasih N, Irfan S, Zafar A, et al. J Pak Med Assoc Vol 60, No 9, September 2010, p 750-53.

2. Lecrecq R. Mechanisms of resistance to macrolides and lincosamides. Nature of resistance elements and clinical implications. Clin Infect Dis (2002);34(4):482-492. Doi 10.10.86/324626.

3. Isenberg HD. Essential procedures for clinical microbiology. 1998. ASM Press. Washington DC.

4. CLSI. Performance standards for antimicrobial susceptibility testing; twenty-fifth informational supplement. CLSI document M100-25. Clinical Laboratory Standards Institute 2015, Wayne, PA.

5. Patel AK, Patel KK, Patel KR, et al. Time trends in the epidemiology of microbial infections at a tertiary care centre in west India over last five years. J Assoc Physicians India 2010;58 (suppl):37-40.
6. Gopalakrishnan R, Suresh Kumar D. Changing trends in antimicrobial susceptibility and hospital acquired infections over an eight year period in a tertiary care hospital in relation to introduction of infection control programme. J Assoc Physicians India 2010; 58(Suppl):25-31.

7. Raghavendra Rao AV, Kavitha A, Seetha KS. Prevalence of inducible clindamycin resistance among clinical isolates of staphylococcus. National Journal of Basic Medical Sciences, Volume-III, Issue-1, 68-71.

8. Patel M, Waites KB, Moser SA, et al. Prevalence of inducible clindamycin resistance among communityand hospital-associated Staphylococcus aureus isolates. Journal of Clinical Microbiology, July 2006, p. 24812484, Vol 44, No 7.

9. Deotale $\mathrm{V}$, Mendiratta $\mathrm{DK}$, Raut $\mathrm{U}$, et al. Inducible clindamycin resistance in Staphylococcus aureus isolated from clinical samples. Indian J Med Microbiol 2010;28:124-6.

10. Yilmaz G, Aydin K, Iskender S, et al. Detection and prevalence of inducible clindamycin resistance in Staphylococcus. J Med Microbiol 2007;56:342-5.

11. Azap OK, Arslan H, Timurkaynak F, et al. Incidence of inducible clindamycin resistance in Staphylococcus: first results from Turkey. Clin Microbiol Infect 2005; 11:582-584.

12. Shantala GB, Adithi S Shetty, Rahul Rao K, et al. Detection of inducible clindamycin resistance in clinical isolates of Staphylococcus aureus by the disc diffusion induction test. Journal of Clinical and Diagnostic Research [serial online] 2011 February [cited:2012 Jul 1]; 5:35-37.

13. Gupta V, Datta P, Rani H, et al. Inducible clindamycin resistance in Staphylococcus aureus: a study from North India. J Post Grad Med 2009;55:176-9.

14. Gadepalli R, Dhawan B, Mohanty S, et al. Inducible clindamycin resistance in clinical isolates of Staphylococcus aureus. Indian J Med Res 2006;123:5713.

15. Prabhu K, Rao S, Rao V. Inducible clindamycin resistance in Staphylococcus aureus isolated from clinical samples. J Lab Physicians 2011;3:25-7. 